Article

\title{
Reactivity Comparison of $\omega$-Alkenols and Higher 1-Alkenes in Copolymerization with Propylene Using An Isospecific Zirconocene-MMAO Catalyst
}

\author{
Benard Oloo Nyangoye, Tianyou Li, Long Chen * and Zhengguo Cai * \\ Received: 11 September 2015 ; Accepted: 10 October 2015 ; Published: 16 October 2015 \\ Academic Editor: Changle Chen \\ State Key Laboratory for Modification of Chemical Fibers and Polymer Materials, \\ College of Material Science and Engineering, Donghua University, 2999 North Renmin Road, \\ Shanghai 201620, China; benardnyangoye@yahoo.com (B.O.N.); 18818231465@163.com (T.L.) \\ * Correspondence: happyjack@dhu.edu.cn (L.C.); caizg@dhu.edu.cn (Z.C.); Tel./Fax: +86-21-67792453 (Z.C.)
}

\begin{abstract}
Copolymerizations of propylene with $\omega$-alkenols (aluminum-protected 5-hexene-1-ol $(\mathrm{AH})$ and 10-undecene-1-ol (AU)) and non-polar analogues (1-hexene and 1-dodecene) were conducted with a rac-[Me $\left.\mathrm{M}_{2} \mathrm{Si}(2-\mathrm{Me}-4-\mathrm{Ph}-\mathrm{Ind})_{2}\right] \mathrm{ZrCl}_{2}$ activated by modified methylaluminoxane. The catalytic system showed high activity for each copolymerization, of which value was independent on the comonomer used and decreased with the increase of the comonomer concentration. The comonomer content of the copolymers obtained also decreased with the increase of the comonomer concentration in each copolymer. The evaluation of the monomer reactivity ratios indicates a preference for the propylene insertion regardless of the last inserted monomer unit in growing polymer chain in all the copolymerizations. The relative reactivity of $\omega$-alkenols was however significantly lower than that of non-polar analogues. These results suggested that the aluminum protection of polar monomer do not affect the activity of copolymerization but significantly decrease the comonomer reactivity.
\end{abstract}

Keywords: metallocene; propylene; $\omega$-alkenol; copolymerization; reactivity

\section{Introduction}

Polyolefins having polar functionalized side groups have a greater demand due to their unique properties such as adhesion, toughness, print/paintability, miscibility and rheological properties $[1,2]$. The direct copolymerization of olefin with polar functional monomer is an efficient method for the synthesis of functionalized polyolefins with control of the amount of functional group and their distribution in the polymer backbone. The recent developments of single-site catalysts, based on metallocene catalyst, have achieved this copolymerization via coordination-insertion polymerization [3-6]. Late transition metal catalysts are widely applied in the area of the direct copolymerization of functional groups with ethylene, since they are more tolerant to the functional groups and thus applicable to copolymerize the polar functional monomers [5,6]. Early transition metal catalysts require more complicated condition such as the use of functional group protection method, because these catalysts are more sensitive to the functional groups [3]. Among the protection methods, the alkylaluminum-protected polar allyl comonomers possessing long methylene spacer with a terminal functional group are commonly used.

The copolymerization of ethylene with alkylaluminum-protected polar comonomer has been studied extensively for the synthesis of functionalized polyethylene bearing alcohol [7-18], ester $[8,9,19,20]$, ether $[10,21]$, and acid functionalities $[8,9,11,17]$. However, the copolymerization activity of almost all of these catalytic systems dropped significantly compared to the homopolymerization 
of ethylene. Recently, several new early transition catalysts have been developed to copolymerize ethylene and polar comonomers with high activity and good contents of comonomer. For example, Fujita et al. reported the copolymerization of ethylene with hex-5-en-1-ol(5-hexene-1-yl-acetate) using bis(phenoxyimine)titanium catalyst with an activity of $5.15 \times 10^{2} \mathrm{~kg}$-polymer mol-Ti ${ }^{-1} \cdot \mathrm{h}^{-1}$ and $0.74 \mathrm{~mol} \%$ of comonomer content, and the comonomer content increased with raising the comonomer concentration and reached $\sim 3.20 \mathrm{~mol} \%$ accompanied by the significant decrease of activity $\left(15 \mathrm{~kg}\right.$-polymer mol- $\left.\mathrm{Ti}^{-1} \cdot \mathrm{h}^{-1}\right)$ [22]. Li et al. reported that bis( $\beta$-enaminoketonato)titanium catalysts copolymerized ethylene with trialkylaluminum-protected 5-norbornene-2-methanol with an activity of 2,500 kg-polymer mol- $\mathrm{Ti}^{-1} \cdot \mathrm{h}^{-1}$ and $5.3 \mathrm{~mol} \%$ of comonomer content [23]. Tang, Sun and co-workers reported that titanium complexes bearing [ONX] tridentate ligands are highly active in the copolymerization of ethylene with various aluminum-protected polar comonomers with highest activity of $130,000 \mathrm{~kg}$-polymer mol-Ti ${ }^{-1} \cdot \mathrm{h}^{-1}$ and a comonomer content of $3.3 \mathrm{~mol} \%[24,25]$.

On the other hand, the examples of copolymerization of aluminum-protected polar comonomer with propylene are much less than those with ethylene. Late transition metal catalysts are not suitable for the direct copolymerization of propylene, since control of the stereospecificity is generally difficult with these catalysts in propylene polymerization. Although Ziegler-Natta and metallocene catalysts can be applicable to functional group protection method, the activity of copolymerization with propylene is much lower than those with ethylene, especially at higher concentration of comonomer $[9,26]$. Seppala et al. succeeded in increasing the copolymerization activity by changing the proportion of methyl aluminoxane (MAO) in the mixture of MAO and triisobutylaluminum (TIBA) used as cocatalyst [27]. Hagihara et al. have achieved the synthesis of functionalized polypropylene with precise control of the arrangement of polar group from the inner of main chain to the chain end $[28,29]$.

Much effort has been paid for the improvement of copolymerization activity and the control of the microstructure of functionalized polyolefins by adjusting the polymerization condition and the structure of catalyst and comonomer. However, there are no evidences for the effect of aluminum protected polar group on copolymerization behavior in detail. In this work, we investigated the copolymerization of propylene with TIBA protected $\omega$-alkenols (5-hexen-1-ol and 10-undecen-1-ol) and non-polar analogues (1-hexene and 1-dodecene) using isospecific zirconocene $\left[\mathrm{Me}_{2} \mathrm{Si}(2-\mathrm{Me}-4-\mathrm{Ph}-\mathrm{Ind})_{2}\right] \mathrm{ZrCl}_{2}$ activated with modified MAO (MMAO) and 2,6-di-tert-butyl-4-methylphenol (BHT), respectively. Interestingly, the comparison results of copolymerization indicate that protecting group is not the main reason for the decrease of the copolymerization activity but can dramatically influence the comonomer reactivity.

\section{Experimental Section}

\subsection{Materials}

All operations were performed under nitrogen gas using standard Schlenk techniques and all solvents were purified by a solvent purification system. Research grade propylene was purified by passing it through dehydration column of ZHD-20 and deoxidation column of ZHD-20A. All comonomers (Chem Greatwall, Wuhan, China) were dried over calcium hydride and freshly distilled before use. TIBA-protected $\omega$-alkenols were prepared according to literature [13]. Zirconocene ([Me $\left.2 \mathrm{Si}(2-\mathrm{Me}-4-\mathrm{Ph}-\mathrm{Ind})_{2}\right] \mathrm{ZrCl}_{2}$ ) was obtained from Boulder Scientific company (Longmont, CO, USA) and used without further purification.

\subsection{Polymerization Procedure}

At first, a $100 \mathrm{~mL}$ glass flask equipped with a magnetic stirrer was charged with certain amounts of toluene, MMAO, BHT and comonomer. After the solution was saturated by propylene under atmospheric pressure, polymerization was initiated by the addition of zirconocene/toluene solution. 
The copolymerization was terminated by the addition of acidic ethanol. The copolymers obtained were washed with ethanol and then dried under vacuum at $60^{\circ} \mathrm{C}$ for $6 \mathrm{~h}$.

\subsection{Analytical Procedure}

Molecular weights and molecular weight distributions of copolymers were measured by a polymer laboratory PL GPC-220 (Agilen, Santa Clara, CA, USA) at $150^{\circ} \mathrm{C}$ using trichlorobenzene as a solvent and calibrated by polystyrene standards. The ${ }^{1} \mathrm{H}$ and ${ }^{13} \mathrm{C}$ NMR spectra of the copolymers were recorded a Bruker Ascend ${ }^{\mathrm{TM}} 400$ spectrometer (Bruker, Karlsruhe, Germany) at $120{ }^{\circ} \mathrm{C}$, and the sample solutions were prepared in 1,1,2,2-tetrachloroethane- $d_{2} d_{2}$ and the central peak of the solvent $(74.47 \mathrm{ppM})$ was used as an internal reference. The melting temperatures of the copolymers were measured with a NETZSCH DSC-204F1 differential scanning calorimeter (Netzsch group, Selb, Germany) at a heating rate of $10{ }^{\circ} \mathrm{C} / \mathrm{min}$ from $20-200{ }^{\circ} \mathrm{C}$.

\section{Results and Discussion}

\subsection{Copolymerization of Propylene with $\omega$-Alkenols and Higher 1-Alkenes}

Copolymerizations of propylene with $\omega$-alkenols (TIBA-protected 5-Hexene-1-ol (AH) and TIBA-protected 10-Undecene-1-ol (AU)) and non-polar analogues (1-hexene and 1-dodecene) using a rac-[Me $\mathrm{Mi}_{2} \mathrm{Si}$ (2-Me-4-Ph-Ind) $\left.)_{2}\right] \mathrm{ZrCl}_{2}-\mathrm{MMAO} / \mathrm{BHT}$ catalytic system were conducted in toluene at $25{ }^{\circ} \mathrm{C}$ under an atmospheric pressure of propylene by changing the comonomer feed ratio. We employed BHT as the modifying reagent of trialkylaluminum in MMAO reported by Busico [30]. The results are shown in Table 1. For comparison, homopolymerization of propylene was also conducted (entry 1$)$.

Table 1. Copolymerizations of propylene with $\omega$-alkenols and higher 1-alkenes using rac- $\left[\mathrm{Me}_{2} \mathrm{Si}(2-\mathrm{Me}-4-\mathrm{Ph}-\mathrm{Ind})_{2}\right] \mathrm{ZrCl}_{2}-\mathrm{MMAO} / \mathrm{BHT}^{\mathrm{a}}$.

\begin{tabular}{|c|c|c|c|c|c|c|c|c|}
\hline Entry & $\begin{array}{l}\text { Comonomer }{ }^{b} \\
\text { Feed (mmol) }\end{array}$ & $\begin{array}{l}\text { Yield } \\
\text { (g) }\end{array}$ & $\begin{array}{l}\text { Activity }^{c} \\
\quad\left(10^{3}\right)\end{array}$ & $M_{\mathrm{n}}^{\mathrm{d}}\left(10^{4}\right)$ & $M_{\mathrm{W}} / M_{\mathrm{n}}{ }^{\mathrm{d}}$ & $\begin{array}{l}\text { Comonomer } \\
\text { Content } \\
(\operatorname{mol} \%)\end{array}$ & $\begin{array}{c}\text { Comonomer } \\
\text { Conversion } \\
(\%)\end{array}$ & $T_{\mathrm{m}}{ }^{\mathrm{g}}\left({ }^{\circ} \mathrm{C}\right)$ \\
\hline 2 & $\mathrm{AH}(3.0)$ & 0.28 & 10 & 18.0 & 2.2 & 2.7 & 4.9 & 143 \\
\hline 3 & $\mathrm{AH}(4.0)$ & 0.23 & 8.5 & 16.4 & 2.1 & 3.5 & 3.8 & 136 \\
\hline 4 & $\mathrm{AH}$ (5.3) & 0.17 & 6.5 & 11.0 & 2.3 & 4.7 & 2.8 & 132 \\
\hline 7 & $\mathrm{AU}(4.0)$ & 0.26 & 9.3 & 18.2 & 2.1 & 3.8 & 5.1 & 117 \\
\hline 8 & AU (5.3) & 0.20 & 7.2 & 16.5 & 2.3 & 5.0 & 3.7 & 107 \\
\hline 9 & $\mathrm{AU}(6.3)$ & 0.16 & 5.8 & 9.7 & 2.2 & 6.1 & 2.8 & 98.6 \\
\hline 10 & $\mathrm{H}(3.0)$ & 0.28 & 10 & 10.2 & 1.7 & 7.2 & 14 & 95.9 \\
\hline 11 & $\mathrm{H}(4.0)$ & 0.25 & 9.0 & 9.1 & 1.7 & 8.7 & 12 & 80.5 \\
\hline 16 & D (5.3) & 0.24 & 8.6 & 6.9 & 1.9 & 10 & 8.6 & 84.9 \\
\hline 17 & $\mathrm{D}(6.3)$ & 0.19 & 6.8 & 5.8 & 1.8 & 11 & 6.2 & 79.5 \\
\hline
\end{tabular}

${ }^{\text {a }}$ Polymerization conditions: total volume $50 \mathrm{~mL}$, temperature $=25^{\circ} \mathrm{C}, \mathrm{Zr}=5 \mu \mathrm{mol}$, MMAO $=10 \mathrm{mmol}$, time $=20 \mathrm{~s}$, propylene $=1.0 \mathrm{~atm} ;{ }^{\mathrm{b}}$ Comonomer: $\mathrm{AH}=$ TIBA-protected 5 -Hexene-1-ol, $\mathrm{AU}=$ TIBA-protected 10-Undecene-1-ol, $\mathrm{H}=1$-hexene, $\mathrm{D}=$ dodecene; ${ }^{\mathrm{c}}$ Activity in $\mathrm{kg}$-polymer mol- $\mathrm{Zr}^{-1} \cdot \mathrm{h}^{-1}$; ${ }^{\mathrm{d}}$ Determined by GPC using polystyrene standard; ${ }^{\mathrm{e}}$ Determined by ${ }^{1} \mathrm{H}$ NMR or ${ }^{13} \mathrm{C}$ NMR; ${ }^{\mathrm{f}}$ Calculated from yield and comonomer content; ${ }^{g}$ Determined by DSC; ${ }^{\mathrm{h}}$ Not detected.

To control the conversion of comonomer, the copolymerization time was made very short since the catalytic system had a very high activity at the $\mathrm{Al} / \mathrm{Zr}$ ratio used, which prevents the precise evaluation of the comonomer reactivity ratios. Although all the copolymerization showed lower activity than homopolymerization, the activity of copolymerization with functional monomer 
was almost the same with that of copolymerization with non-functional monomer. The activity decreased with raising the comonomer concentration regardless of the comonomer used, however, it is interesting to note that the copolymerization activity with polar monomers still showed a high activity of $5100 \mathrm{~kg}$-polymer mol- $\mathrm{Zr}^{-1} \cdot \mathrm{h}^{-1}$ even at high comonomer concentration. These results imply that no deactivation occurred even in the presence of a large amount of aluminum protected polar monomers.

All the copolymerization systems gave high molecular weight copolymers with narrow molecular weight distribution (MWD: 1.7-2.4) and the $M_{\mathrm{n}}$ value of copolymers decreased with increasing the comonomer concentration in each copolymerization system.

\subsection{Microstructure of Copolymers}

The contents of functional and non-functional comonomers in the copolymers were determined with ${ }^{1} \mathrm{H}$ NMR and ${ }^{13} \mathrm{C}$ NMR (Figure 1) spectra, respectively. The content of the polar comonomer can be calculated from the integral ratio of $-\mathrm{CH}_{2} \mathrm{OH}$ methylene proton at $3.63 \mathrm{ppm}$ in ${ }^{1} \mathrm{H} \mathrm{NMR}$ spectrum [27]. The typical ${ }^{13} \mathrm{C}$ NMR spectrum of non-functional copolymer was shown in Figure 1B, and the content was calculated according to the published literature [31].

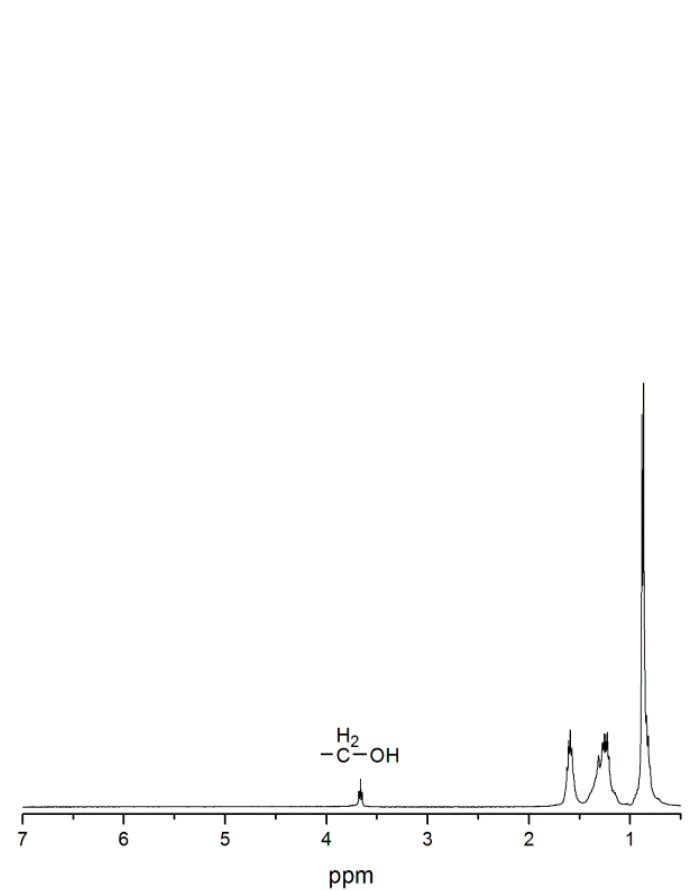

(A)

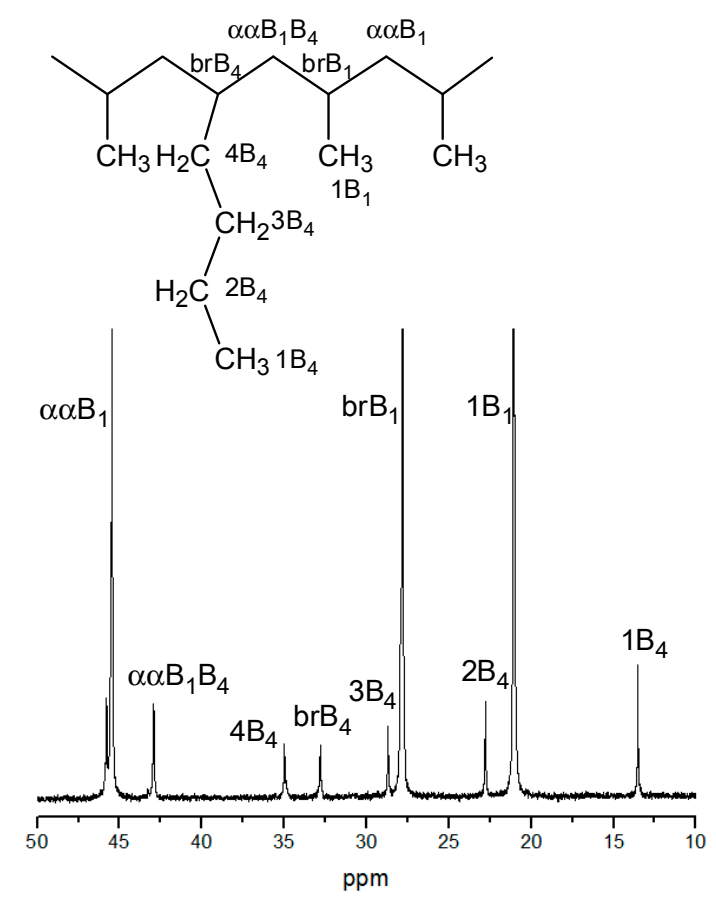

(B)

Figure 1. (A) Typical ${ }^{1} \mathrm{H}$ NMR spectrum of functional copolymer (entry 5); (B) ${ }^{13} \mathrm{C}$ NMR spectrum of non-functional copolymer (entry 10).

The contents of copolymers are plotted against the comonomer concentration in Figure 2. The content increased with the increase of the comonomer concentration in each copolymer. The incorporations of copolymers varied as follows: $2.65-5.73 \mathrm{~mol} \%$ for AH; $2.90-6.11 \mathrm{~mol} \%$ for AU; 7.15-13.41 mol \% for 1-hexene, and 6.30-11.67 mol \% for 1-dodecene. Much lower comonomer content was observed in the functional copolymers compared with that of non-functional copolymers. $\mathrm{AU}$ comonomer which has longer methylene spacer showed higher incorporation than $\mathrm{AH}$, whereas opposite tendency was observed in the copolymers with 1-alkenes. These results indicate that the aluminum protection significantly affected the incorporation of comonomer, and the comonomer reactivity not only depends on the lengths of methylene spacer but also depends on the heteroatom. 


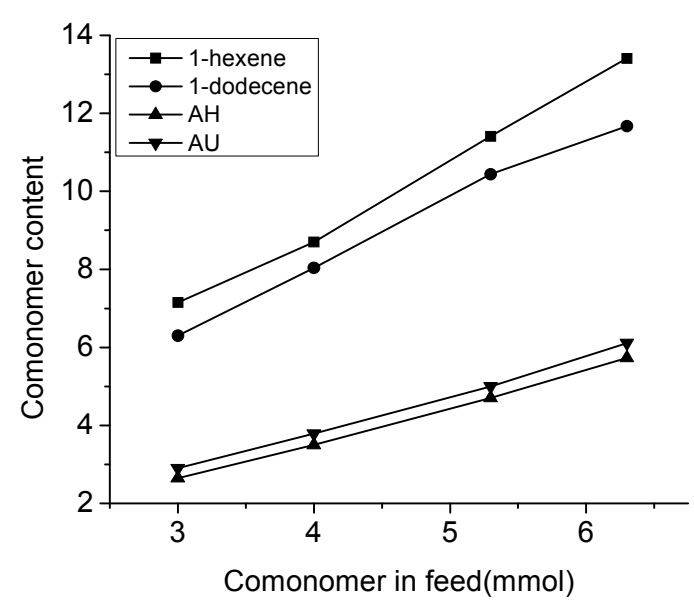

Figure 2. Plots of comonomer content against the comonomer concentration in feed.

\subsection{Comonomer Reactivity Ratios}

Therefore, the comonomer reactivity ratios were determined by using Fineman-Ross method [32] for investigating the relative reactivity of each comonomer.

Fineman-Ross plots and the monomer reactivity ratios of $r_{\mathrm{P}}$ and $r_{\text {comonomer }}$ are shown in Figure 3. These $r_{\mathrm{P}}$ values $(>1)$ indicate a preference for the insertion of propylene regardless of the last inserted monomer unit in each copolymerization. The products of the reactivity ratios $\left(r_{\mathrm{P}} r_{\mathrm{AH}}=6.49\right.$, $\left.r_{\mathrm{P}} r_{\mathrm{AU}}=2.42\right)$ testify a preference for the formation of homopropylene sequence in the functionalized copolymers, whereas the products of the reactivity ratios $\left(r_{\mathrm{P}} r_{\text {hexene }}=0.77, r_{\mathrm{P}} r_{\text {dodecene }}=0.37\right)$ indicate a tendency of the formation of random copolymer. Much lower value of $1 / r_{\mathrm{P}}$ obtained with $\omega$-alkenols testify that the comonomer reactivity is strongly dependent on the aluminum protection probably due to steric hindrance of diisobutyl aluminum, since no deactivation occurred in the copolymerization with $\omega$-alkenols. Higher relative reactivity of AU than AH also support this assumption. However, a little higher value of $1 / r_{\mathrm{P}} \mathrm{r}_{\mathrm{p}}$ was observed in the copolymerization with 1-hexene compared to the value obtained with 1-dodecene, which testify that relative activity of 1 -alkene is not strongly dependent on the methylene spacer lengths of comonomer in this isospecific Zirconocene catalytic system.
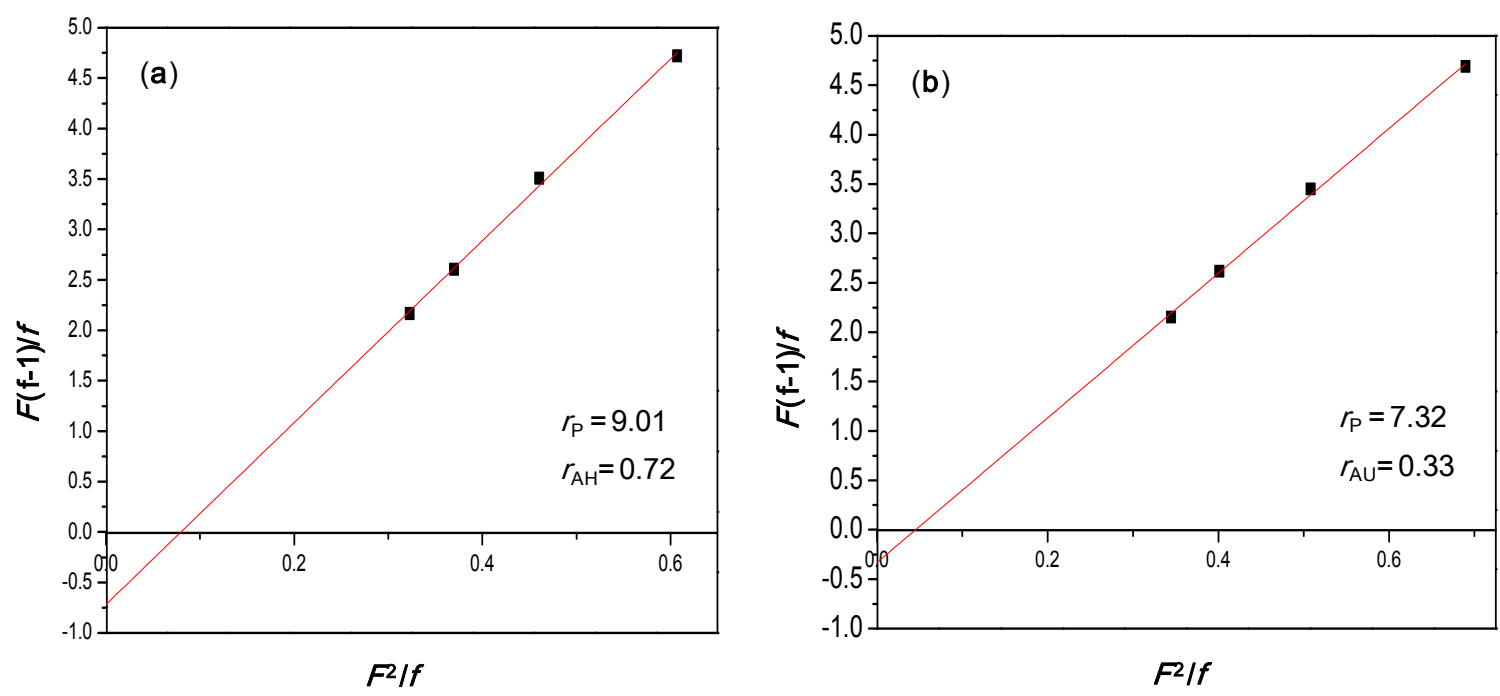

Figure 3. Cont. 

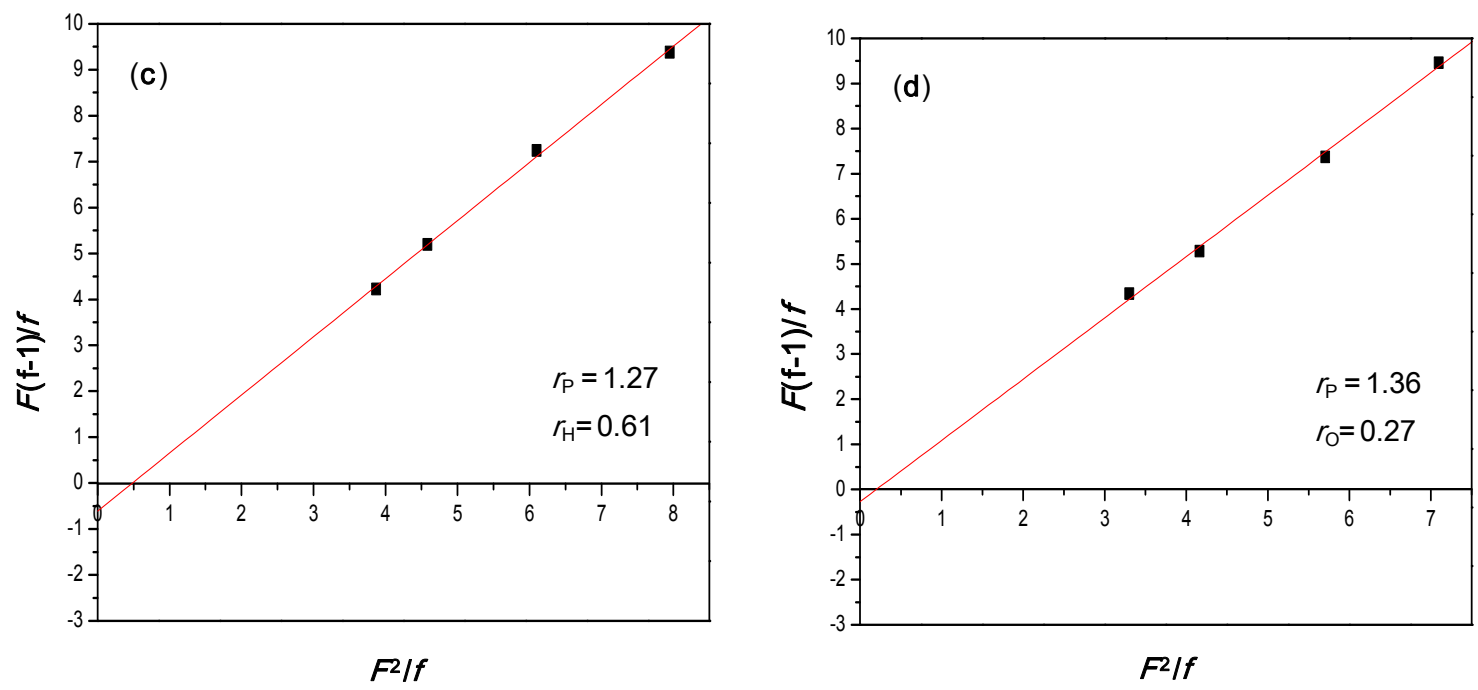

Figure 3. Fineman-Ross plots for copolymerization with 5-hexene-01-ol (AH) (a); 10-undecene-01-ol (AU) (b); 1-hexene (c); and 1-dodecene (d).

\subsection{Thermal Properties of Copolymers}

The $T_{\mathrm{m}}$ value of the copolymers obtained was then investigated by DSC and shown in Table 1. The $T_{\mathrm{m}}$ value decreased with the increase of the comonomer content in each copolymer, and is however dependent on the comonomer used.

\section{Conclusions}

rac-[Me $\left.\mathrm{Me}_{2} \mathrm{Si}(2-\mathrm{Me}-4-\mathrm{Ph}-\mathrm{Ind})_{2}\right] \mathrm{ZrCl}_{2}-\mathrm{MMAO} / \mathrm{BHT}$ system showed high activity for the copolymerization regardless of the comonomer used, which indicates that aluminum protection do not promote deactivation to affect the activity. The comonomer content of the copolymer obtained was controllable by changing comonomer feed ratio in each copolymerization. The content of polar monomer was however much lower than that of non-polar analogues. The evaluation of the monomer reactivity ratios indicates a preference for the insertion of propylene regardless of the last inserted monomer unit in growing polymer chain, and the comonomer reactivity decreased significantly by the use of aluminum-protected polar monomer.

Acknowledgments: This work was supported by National Natural Science Foundation of China (21174026), Program for New Century Excellent Talents in University, the Program for Professor of Special Appointment (Eastern Scholar) at Shanghai Institutions of Higher Learning, "Shu Guang" project supported by Shanghai Municipal Education Commission and Shanghai Education Development Foundation and the Fundamental Research Funds for the Central Universities. We thank Tosoh-Finechem Corporation Co. for donating MMAO.

Author Contributions: All authors tried their best to contribute effectively to perform and analyze this experimental work. They all participated to the writing of the present manuscript. Benard Oloo Nyangoye performed the overall experimental work. Tianyou Li participated in analysis of structural data. The settings up of the experimental protocols as well as the interpretation of the obtained results were performed under the supervision of Long Chen and Zhengguo Cai.

Conflicts of Interest: The authors declare no conflict of interest.

\section{References}

1. Franssen, N.M.G.; Reek, J.N.H.; Bruin, B.D. Synthesis of functional "polyolefins": State of the art and remaining challenges. Chem. Soc. Rev. 2013, 42, 5809-5832. [CrossRef] [PubMed]

2. Dong, J.Y.; Hu, Y. Design and synthesis of structurally well-defined functional polyolefins via transition metal-mediated olefin polymerization chemistry. Coord. Chem. Rev. 2006, 250, 47-65. [CrossRef]

3. Boffa, L.S.; Novak, B.M. Copolymerization of polar monomers with olefins using transition-metal complexes. Chem. Rev. 2000, 100, 1479-1493. [CrossRef] [PubMed] 
4. Chen, E.Y.X. Coordination polymerization of polar vinyl monomers by single-site metal catalysts. Chem. Rev. 2009, 109, 5157-5214. [CrossRef] [PubMed]

5. Nakamura, A.; Ito, S.; Nozaki, K. Coordination-insertion copolymerization of fundamental polar monomers. Chem. Rev. 2009, 109, 5215-5244. [CrossRef] [PubMed]

6. Carrow, B.P.; Nozaki, K. Transition-metal-catalyzed functional polyolefin synthesis: Effecting control through chelating ancillary ligand design and mechanistic insights. Macromolecules 2014, 47, 2541-2555. [CrossRef]

7. Aaltonen, P.; Lofgren, B. Synthesis of functional polyethylenes with soluble metallocene/methylaluminoxane catalyst. Macromolecules 1995, 28, 5353-5357. [CrossRef]

8. Aaltonen, P.; Lofgren, B. Functionalization of polyethylenes via metallocene/methylaluminoxane catalyst. Eur. Polym. J. 1997, 33, 1187-1190. [CrossRef]

9. Hakala, K.; Lofgren, B.; Helaja, T. Copolymerizations of oxygen-functionalized olefins with propylene using metallocene/methylaluminoxane catalyst. Eur. Polym. J. 1998, 34, 1093-1097. [CrossRef]

10. Hakala, K.; Helaja, T.; Lofgren, B. Metallocene/methylaluminoxane-catalyzed copolymerizations of oxygen-functionalized long-chain olefins with ethylene. J. Polym. Sci. Polym. Chem. 2000, 38, 1966-1971. [CrossRef]

11. Marques, M.M.; Correia, S.G.; Ascenso, J.R.; Ribeiro, A.F.G.; Gomes, P.T.; Dias, A.R.; Foster, P.; Rausch, M.D.; Chien, J.C.W. Polymerization with TMA-protected polar vinyl comonomers. I. Catalyzed by group 4 metal complexes with $\eta 5$-type ligands. J. Polym. Sci. Polym. Chem. 1999, 37, 2457-2469. [CrossRef]

12. Hagihara, H.; Murata, M.; Uozumi, T. Alternating copolymerization of ethylene and 5-hexen-1-ol with [ethylene(1-indenyl)(9-fluorenyl)]-zirconium dichloride/methylaluminoxane as the catalyst. Macromol. Rapid Commun. 2001, 22, 353-357. [CrossRef]

13. Hagihara, H.; Tsuchihara, K.; Takeuchi, K.; Murata, M.; Ozaki, H.; Shiono, T. Copolymerization of ethylene or propylene with $\alpha$-olefins containing hydroxyl groups with zirconocene/methylaluminoxane catalyst. J. Polym. Sci. Polym. Chem. 2004, 42, 52-58. [CrossRef]

14. Imuta, J.; Kashiwa, N.; Toda, Y. Catalytic regioselective introduction of allyl alcohol into the nonpolar polyolefins: Development of one-pot synthesis of hydroxyl-capped polyolefins mediated by a new metallocene IF catalyst. J. Am. Chem. Soc. 2002, 124, 1176-1177. [CrossRef] [PubMed]

15. Kawahara, N.; Kojoh, S.; Matsuo, S.; Kaneko, H.; Matsugi, T.; Kashiwa, N. Investigation of insertion reaction of 10-undecen-1-ol protected with alkylaluminum in $\mathrm{En}(\mathrm{Ind})_{2} \mathrm{ZrCl}_{2} / \mathrm{MAO}$ Catalyst System. J. Mol. Catal. A Chem. 2005, 241, 156-161. [CrossRef]

16. Zhang, X.; Chen, S.; Li, H.; Zhang, Z.; Lu, Y.; Wu, C.; Hu, Y. Highly active copolymerization of ethylene with 10-undecen-1-ol using phenoxy-based zirconium/methylaluminoxane catalysts. J. Polym. Sci. Polym. Chem. 2005, 43, 5944-5952. [CrossRef]

17. Zhang, X.; Chen, S.; Li, H.; Zhang, Z.; Lu, Y.; Wu, C.; Hu, Y. Copolymerizations of ethylene and polar comonomers with bis(phenoxyketimine) group IV complexes: Effects of the central metal properties. J. Polym. Sci. Polym. Chem. 2007, 45, 59-68. [CrossRef]

18. Huang, Y.; Yang, K.; Dong, J.Y. Copolymerization of ethylene and 10-undecen-1-olusing a montmorillonite-intercalated metallocene catalyst: Synthesis of polyethylene/montmorillonite nanocomposites with enhanced structural stability. Macromol. Rapid Commun. 2006, 27, 1278-1283. [CrossRef]

19. Purgett, M.D.; Vogl, O. Functional Polymers. XLIX. Copolymerization of $\omega$-alkenoates with $\alpha$-olefins and Ethylene. J. Polym. Sci. Polym. Chem. 1989, 27, 2051-2063. [CrossRef]

20. Zuo, W.; Zhang, M.; Sun, W.H. Imino-iindolate half-titanocene chlorides: Synthesis and their ethylene (co-)polymerization. J. Polym. Sci. Polym. Chem. 2009, 47, 357-372. [CrossRef]

21. Fernandes, M.; Kaminsky, W. Copolymerization of ethylene with 2,7-octadienyl methyl ether in the presence of metallocene and nickel diimine catalysts. Macromol. Chem. Phys. 2009, 210, 585-593. [CrossRef]

22. Terao, H.; Ishii, S.; Mitani, M.; Tanaka, H.; Fujita, T. Ethylene/polar monomer copolymerization behavior of bis(phenoxy-imine)ti complexes: Formation of polar monomer copolymers. J. Am. Chem. Soc. 2008, 130, 17636-17637. [CrossRef] [PubMed]

23. Hong, M.; Wang, Y.X.; Mu, H.L.; Li, Y.S. Efficient synthesis of hydroxylated polyethylene via copolymerization of ethylene with 5-norbornene-2-methanol using bis( $\beta$-enaminoketonato)titanium catalysts. Organometallics 2011, 30, 4678-4686. [CrossRef] 
24. Yang, X.H.; Liu, C.R.; Wang, C.; Sun, X.L.; Guo, Y.H.; Wang, X.K.; Wang, Z.; Xie, Z.; Tang, Y. $\left[\mathrm{O}^{-} \mathrm{NS}^{\mathrm{R}}\right] \mathrm{TiCl}_{3}$-catalyzed copolymerization of ethylene with functionalized olefins. Angew. Chem. Int. Ed. 2009, 48, 8099-8102. [CrossRef] [PubMed]

25. Chen, Z.; Li, J.F.; Tal, W.J.; Sun, X.J.; Yang, X.H.; Tang, Y. Copolymerization of ethylene with functionalized olefins by [onx] titanium complexes. Macromolecules 2013, 46, 2870-2875. [CrossRef]

26. Aaltonen, P.; Fink, G.; Lofgren, B.; Seppala, J. Synthesis of hydroxyl group containing polyolefins with metallocene/methylaluminoxane catalysts. Macromolecules 1996, 29, 5255-5260. [CrossRef]

27. Paavola, S.; Lofgren, B.; Seppala, J. Polymerization of hydroxyl functional polypropylene by metallocene catalysis. Eur. Polym. J. 2005, 41, 2861-2866. [CrossRef]

28. Hagihara, H.; Tsuchihara, K.; Sugiyama, J.; Takeuchi, K.; Shiono, T. Copolymerization of 3-buten-1-ol and propylene with an isospecific zirconocene/methylaluminoxane catalyst. J. Polym. Sci. Polym. Chem. 2004, 42, 5600-5607. [CrossRef]

29. Hagihara, H.; Ishihara, T.; Ban, H.T.; Shiono, T. Precise control of microstructure of functionalized polypropylene synthesized by the ansa-zirconocene/mao catalysts. J. Polym. Sci. Polym. Chem. 2008, 46, 1738-1748. [CrossRef]

30. Busico, V.; Cipullo, R.; Cutillo, F.; Friederichs, N.; Ronca, S.; Wang, B. Improving the performance of methylalumoxane: A facile and efficient method to trap "free" trimethylaluminum. J. Am. Chem. Soc. 2003, 125, 12402-12403. [CrossRef] [PubMed]

31. Kissin, Y.V.; Brandolini, A.J. ${ }^{13}$ C NMR spectra of propylene/1-hexene copolymer. Macromolecules 1991, 24 , 2632-2633. [CrossRef]

32. Fineman, R.; Ross, S.D. Linear method for determining monomer reactivity ratios in copolymerization. J. Polym. Sci. Polym. Chem. 1950, 5, 259-262. [CrossRef]

(C) 2015 by the authors; licensee MDPI, Basel, Switzerland. This article is an open access article distributed under the terms and conditions of the Creative Commons by Attribution (CC-BY) license (http://creativecommons.org/licenses/by/4.0/). 